\title{
A RELAÇÃO ENTRE REDES SOCIAIS E AUTOESTIMA
}

\section{THE RELATIONSHIP BETWEEN SOCIAL NETWORKS AND SELF-ESTEEM}

\section{Marina da Conceição Silva ${ }^{\mathrm{I}}$}

RESUMO: O presente trabalho aborda a relação entre as redes sociais e a formação da autoestima do indivíduo, visto que é notável a presença e significância das mídias sociais no mundo atual. Tal preocupação justifica-se pela quantidade de indivíduos que medem sua capacidade e/ou beleza física a partir da opinião dos demais nas redes sociais, resultando assim, em problemas de autoestima, que refere-se a um componente do autoconceito, que diz respeito aos afetos e emoções que acompanham a descrição de nós mesmos. O artigo enquadra-se como uma pesquisa de campo em uma metodologia qualitativa, visto que, como meio de verificar tal necessidade, realizou-se um questionário com 25 pessoas de 13 a 49 anos residentes na cidade de Dom Pedro- Maranhão no qual abordou-se a preocupação supracitada, além de obter as opiniões dos mesmos sobre o tema, denotando ainda os sentimentos destas em sua própria relação mídia social $\mathrm{x}$ autoestima. $\mathrm{O}$ estudo baseia-se ainda em artigos e pesquisas de autores como Rogers, Vila Nova e Guilhard. A partir destas ferramentas podese constatar que faz-se necessário um amplo processo de reflexão pessoal e auto aceitação dos indivíduos, visto que grande parte da população busca desenfreadamente a aprovação dos demais para avaliar a si próprio, além de viver constantemente em prol de chegar a um padrão de vida estabelecido nas redes sociais que é inalcançável, resultando em desapontamentos e deficiências interiorizadas.

PALAVRAS-CHAVE: Redes Sociais. Autoestima. Exposição. Frustração

ABSTRACT: The present work deals with the relationship between social networks and the formation of self-esteem of the individual, since the presence and significance of social media in today's world is remarkable. This concern is justified by the number of individuals who measure their capacity and/or physical beauty from the opinion of others in social networks, thus resulting in problems of self-esteem, which refers to a component of self-concept, which concerns the affections and emotions that accompany the description of ourselves. The article fits as a field research in a qualitative methodology, since, as a means to verify such need, a questionnaire was carried out with 25 people from 13 to 49 years old living in the city of Dom Pedro-Maranhão, in which the aforementioned concern was approached, besides obtaining their opinions on the subject, also denoting their feelings in their own social media $\mathrm{x}$ self-esteem relationship. The study is also based on articles and research by authors such as Rogers, Vila Nova and Guilhard. From these tools it can be seen that a broad process of personal reflection and self-acceptance of individuals is necessary, since a large part of the population unrestrainedly seeks the approval of others to evaluate themselves, besides living constantly in favor of reaching a standard of living established in social networks that is unreachable, resulting in disappointments and deficiencies internalized.

KEYWORDS: Social Networks. Self-esteem. Exposure. Frustration

\footnotetext{
I Pós Graduada em Gestão e Supervisão Escolar, Graduada em Pedagogia. E-mail: marinasilva25@gmail.com
} 


\section{INTRODUÇÃO}

É sábio que estamos vivendo em um período de globalização, no qual a troca de informações, o conhecimento e as notícias acontecem a todo instante. Nesse contexto, as mídias sociais acabam ganhando cada vez mais espaço na vida das pessoas tornando-se uma das principais formas de se relacionar.

Redes sociais e meios digitais de comunicação impactaram profundamente nos valores da nossa sociedade, tornando aparências, status e idealizando uma 'vida perfeita'. Essa mudança de valores, ainda que em constante transformação, pode se transformar em gatilho de sofrimento, uma vez que somos diariamente apresentados a um estereótipo de beleza e estilo de vida que não é facilmente alcançável e isto pode gerar mal-estar.

O presente artigo objetiva identificar de que forma o uso constante das redes sociais afetam ou interferem na autoestima dos indivíduos, tendo em vista que devemos refletir sobre a indústria cultural na busca pela beleza e o protagonismo da imagem nas redes sociais, tendo como parâmetro de aceitação e julgamento positivo a obtenção dos likes e quando tais expectativas não realizam-se ocorre uma frustração que abala a autoimagem do indivíduo.

Tal pesquisa justifica-se pelo fato de que as mídias sociais desempenham atualmente um papel muito importante na forma como grande parte das pessoas se veem. Nossa imagem corporal é parte central de nossa autoimagem, pois é também a partir dela que construímos nosso senso de identidade. Ou seja: não se trata de uma questão de simples vaidade pessoal, mas algo, de fato, real e muito importante.

Como método para compreender significativamente esta relação aplicou-se um questionário com um grupo de 25 pessoas da faixa etária de 13 a 49 anos residentes na cidade de Dom Pedro - Maranhão por meio da plataforma do Google, Forms.app, no qual os entrevistados explicitaram suas opiniões sobre o uso das redes sociais em aspecto individual e social. Assim, tal pesquisa enquadra-se como pesquisa de observação em campo com abordagem qualitativa. 
O trabalho divide-se em dois capítulos. No primeiro compreende-se a presença constante e irrefutável das redes sociais no cotidiano dos indivíduos, de modo que devemos adequarmo-nos a seu uso e buscar transformá-las em algo positivo em aspectos pessoais e profissionais. E no segundo capítulo, aborda-se de fato a relação desta com a formação da autoestima do ser.

\section{I- AS REDES SOCIAIS NO COTIDIANO}

Pesquisas, notícias, memes, fotos, vídeos, compras, vendas e troca constante e intensa de informações. Este é um resumo do dia a dia atual diante das redes sociais, nos quais temse acesso a qualquer informação que se deseje. Com os aparelhos eletrônicos cada vez mais modernos, o mundo todo encontra-se na palma da mão.

Percebe-se, atualmente, o poder que as mídias sociais conquistaram e vem conquistando. Grandes líderes mundiais utilizam-se desses meios para se comunicarem com o mundo, presidentes de vários países fazem pronunciamentos e anúncios através de seus perfis em redes sociais, e até o Papa, representante máximo da igreja católica, possui perfis em redes sociais para falar com seus fiéis buscando a evangelização das pessoas. Tudo o que esses líderes importantes postam logo torna-se de conhecimento do resto do mundo, ultrapassa as fronteiras de seus países, vira notícia mundial. Por isso, não se pode considerar as mídias sociais como algo externo a essa sociedade atual, pois esta é construída socialmente, feita pela e para as pessoas, nem deve se pensar em tecnologia como algo separado influenciando essa sociedade ou vice e versa, pois ambas se constituem mutuamente (MACKENZIE E WAJCMAN, I9995 apud PRIMO, 2012 p.625).

As mídias sociais têm mostrado seus pontos positivos e negativos. Atualmente são utilizadas para uma diversidade de atividades, que sempre alcançam um número significativo de pessoas por seu poder de disseminação. Como ponto positivo vale destacar seu uso por pessoas que estão passando por situações difíceis para compartilhar seus sofrimentos, dores, angústias, por exemplo, é cada vez mais comum que se veja pessoas que estão com alguma enfermidade se utilizarem de blogs para expor o dia a dia da doença, os 
desafios, as superações, e receberem o apoio de outros que passam ou até mesmo convivem com pessoas que passam pela mesma situação. Pode-se citar também a criação de diversos empregos on-line, auxílio a pessoas menos favorecidas e a facilidade em comunicar-se com pessoas que encontram-se fisicamente distantes.

No entanto, percebe-se também um outro lado das redes sociais que nem sempre trazem aspectos positivos. Dentre estes, pode-se citar a grande exposição e busca por aprovação das pessoas nas redes sociais. O desejo desenfreado por likes e comentários nas postagens e a frustração causada quando não se alcança o objetivo desejado.

Denota-se ainda a 'falsa felicidade' esculpida nas redes sociais, nos quais as pessoas mostram apenas o que querem que os demais vejam, como forma de alcançar uma fama virtual. Pode-se notar que ao comparar-se constantemente a outras pessoas, corpos e estilos de vida, especialmente e utilizar como referência postagens em redes sociais, adentra-se em um caminho perigoso. Ao assumirmos como parâmetro o mundo da aparência, damos combustível para uma baixa autoestima, fragilizando não apenas nossas relações interpessoais, mas também a relação com o nosso próprio corpo.

\section{I- A EXPOSIÇÃO NAS REDES SOCIAIS}

$\mathrm{Na}$ atualidade, compartilhamos momentos das nossas vidas através da internet constantemente. Com a importância que as redes sociais adquiriram ao longo dos últimos anos, a inclusão de celulares, tablets e computadores na rotina diária das pessoas acabou remodelando alguns de seus comportamentos.

Por isso, o psicanalista, doutor em Psicologia Social e consultor de treinamento e desenvolvimento organizacional Antônio Carlos de Barros Júnior escreveu sua tese de doutorado, defendida no Instituto de Psicologia da USP, "Quem vê perfil não vê coração: a ferida narcísica de desempregados e a construção de imagens de si no Facebook e no LinkedIn”. 
No trabalho, o pesquisador afirma que, tanto no mundo real quanto no mundo virtual, vivemos uma "sociedade do espetáculo narcísico", porque nos esforçamos para tentar atrair e cativar o público, quase que numa tentativa de nos vender como produtos indispensáveis e da mais alta tecnologia. Mas na internet a exposição parece ser ainda mais explícita, porque, segundo ele, as redes sociais agem como uma espécie de vitrine na qual as pessoas tentam se manter “"vendáveis' o tempo todo”.

Dessa forma, as pessoas almejam a cada dia conseguir mais seguidores, visualizações, curtidas e comentários em suas redes sociais. Assim, percebe-se o grau de importância que muitas pessoas dão aos status virtuais, criando muitas vezes ficções apenas para tornar-se 'interessante' aos olhos dos demais.

Como consequência, denota-se a grande exposição diária nas redes sociais desde o momento em que acorda até o anoitecer, envolvendo o que come, onde vai, o que faz, o que veste, com quem anda, enfim, um verdadeiro diário aberto e acessível, muitas vezes mascarado pela busca por fama e poder virtual.

Voltamo-nos assim ao que o psicanalista supracitado denomina de 'sociedade do espetáculo narcísico', tendo em vista que a exibição constante, a busca por olhares e aprovações permanece como prioridade para boa parte dos usuários na internet.

O tempo excessivo na frente das telas o pressiona a expor cada detalhe de sua vida também é um fato que chama atenção, visto que tem influenciado o comportamento da grande maioria dos indivíduos que acessam as redes sociais.

Ficamos divididos entre a exposição excessiva, liberdade de nos expressar, abrindo mão da segurança. Abrimos mão da segurança em prol da liberdade, trocamos a segurança, para atingirmos um ápice fictício de liberdade e exposição. Pois a liberdade de expressão associada aos riscos relativos à diminuição da privacidade nos ambientes digitais, pode nos levar a uma situação de hiperexposição, que pode trazer também riscos pessoais presentes ou futuros, tanto da segurança quanto de reputação (GABRIEL, 20I8, p. 69). 
No artigo Hiperexposição pessoal nas redes sociais e seus reflexos no direito, obra de Bruna Marangoni Brancaleone Costa e Irineu Francisco Barreto Junior, os autores dizem que:

Falar de si próprio para um grupo exagerado de amigos virtuais, gera um prazer equivalente ao de se alimentar, ganhar dinheiro, dormir ou se relacionar sexualmente. Em uma conversa formal, as pessoas falam de si cerca de $30 \%$ do tempo, enquanto nas redes sociais este índice sobe para $90 \%$, com possibilidade de um feedback imediato. Isso gera inconscientemente uma sensação de prazer instantâneo, mas não sustentável. A vida virtual é diferente da real. Nas redes sociais não importa quem você é e o que faz, mas o que representa para o mundo com suas postagens. Por isso, quem se expõe em excesso não leva em conta o quanto isso pode lhe prejudicar mais do que quem não age dessa forma. Essas pessoas acham que as consequências serão para todos, mas, na verdade, serão proporcionais à sua exposição. (COSTA, JUNIOR, 2018)

Os autores afirmam ainda que quanto mais ficamos conectados por meio das mídias sociais e do uso das tecnologias e sensores da Internet das Coisas, mais ainda oferecemos nossos dados pessoais, colocando em maiores riscos a nossa segurança, pois para termos acesso a essas tecnologias, passamos nossos dados sensíveis. A hiperexposição está atrelada ao uso compulsivo das mídias sociais, expondo a vida cotidiana, sem ter ideia dos riscos que podem causar, muitos ainda, sequer se preocupam com a segurança da rede. Inicia-se o uso por um habito de informar e acaba por um vício em se expor.

\section{2- REDES SOCIAIS X AUTOESTIMA}

Relacionar redes sociais e autoestima atualmente, torna-se muito fácil, tendo em vista que as pessoas avaliam a si próprias e aos demais a partir de suas exposições na internet. Ao projetar o ideal de felicidade em um corpo e uma vida que não são reais, cria-se a armadilha perfeita que pode dificultar nossa relação com o nosso próprio corpo e com a nossa vida.

Durante a aplicação de um questionário pela Plataforma Formas.app realizado no período de 02 a io de novembro de 2020 com 25 pessoas da faixa etária de 13 a 49 anos, residentes na cidade de Dom Pedro- Maranhão pode-se enfatizar o quanto as redes sociais estão presentes na relação com o modo como o individuo percebe a si próprio. 
Ao serem questionados sobre tal relação, obteve-se respostas como:

"Contribuem para criar uma falsa sensação de felicidade momentânea e/ou uma falsa importância que é gerada para sua aceitação pessoal." (A.R. 2020)

"Porque hoje em dia, cobram que você tenha um corpo ideal, beleza, boas vestimentas, para que seja "aceito" na sociedade, e claro se você acha que não está encaixado nesse padrão atual, consequentemente vai acreditar que não está dentro dos padrões e isso afeta a auto estima de muitos." (J.C.S. 2020)

"A necessidade de aprovação por parte de desconhecidos, a grande circulação de pessoas fazendo procedimentos cirúrgicos com fins apenas estéticos, a propagação do conceito de vida perfeita e a importância de se exibir uma vida de luxo e viagens dos grandes perfis, o padrão estético inalcançável deixam as pessoas tristes com seus corpos, com suas casas e vidas." (F.S)

"Afetam o psicólogo das pessoas por isso que muitas sofrem com depressão por tentar se encaixar no "padrão" que a sociedade impõe" (M.N.S)

"Existe um padrão de beleza a ser seguido que é vendido diariamente. Não atoa os "influencers" sempre estão fazendo intervenções no corpo por meio de permuta a fim de vender aquele padrão quase que inalcançável por seus seguidores.”(D.C.)

"Uma escala de o a ıo, diria que ı. Pois as pessoas são afetada sim pelas redes sociais, onde elas expressa sua felicidade e autoestima através da mesma, mais fora delas como é a sua vida real? Será se é realmente tudo isso que posta de felicidades como se ver nas mídias? Difícil responder os pensamentos humanos." (L.L)

"A implantação de um padrão de beleza está ligado totalmente a isso, com as redes é cada vez mais frequente vermos pessoas padronizadas, botox ali, preenchimento labial aqui, definição de barriga aculá, é impossível não machucar os corpos normais com isso.” (K.S.)

"Quando impõem padrões, disseminam preconceito através de usuários mal intencionados." (P.S.)

Tais opiniões, abrem um leque imenso a respeito do assunto em questão. Denota-se que em recorrentes falas, são citados os padrões criados pela indústria digital da beleza, afetando negativamente aqueles que não adequam-se a este padrão. 
Faz-se também importante destacar o que foi citado como 'felicidade momentânea e aceitação pessoal'. Tais características, primordialmente internas e individuais acabam sendo deslocadas a pessoas desconhecidas, que passam a validar se os conteúdos apresentados são ou não importantes e/ou interessantes o suficiente para tornarem-se virais. Quando isso acontece propositalmente, o indivíduo em questão sente esta 'felicidade' porém, a mesma desfaz-se rapidamente visto que a cada segundo surgem novos assuntos, que acabam por deixar tal indivíduo frustrado e em certos casos, obcecado pela busca desenfreada de views, exposição e fama, tudo em busca de aceitação e formação de uma falsa imagem que seja idolatrada pelos demais.

A partir das declarações obtidas, questionou-se sobre o porquê das pessoas buscarem uma 'auto aprovação' dos demais nas redes sociais, obtendo-se respostas como:

"Porque houve uma transposição da vida real para a virtual. Com seu viés de aceitação social”. (D.J.)

"Porque as vezes as pessoas não se sentem bem consigo mesmo e isso é uma forma de se ajudar". (N.V.)

Porque são hipócritas! "A opinião da família é ruim, tanto faz, aos dos que você nem conhece importa". Quanta alienação da sociedade em meio as mídias sociais. (J.O.)

"Talvez pra ter aquele momento de fama". (S.S.)

"Por que na vida real são muito julgados pelos que os cercam, e geralmente elas procuram ver os que as pessoas de fora vão achar delas". (E.M)

"Por que não se sentem realizadas ou não sabem o que buscar na vida real, para que se sintam realizadas no âmbito pessoal”. (A.M.)

"Porque o ser humano por si só não se sente autossuficiente pra se avaliar, e necessita da aprovação de outros, para se sentir bem". (J.C.S)

"A necessidade de ser visto a carência de atenção e o medo de ser julgado e se mostrar sempre coerência de acordo com os demais, geralmente são pessoas que possuem baixa autoestima e esse afeto virtual os likes e as visualizações são o que a pessoa precisa para se sentir bem e parte de alguma coisa, principalmente com aumento de blogueiros nessas redes as pessoas estão voltando sua atenção a isso e 
a essa possibilidade dessa visibilidade imensa o que seria uma alta dose de afeto virtual e traria uma grande satisfação pessoal, pena que isso se restringe apenas ao âmbito virtual." (F.S)

"Pra poderem se sentirem melhor, se não tiverem a aprovação dos outros elas se submetem a serem o que não são para tentar agradar todo mundo.” (M.N.S.)

"Porque o papel das redes sociais a cada dia mais mostra um padrão de vida e beleza a ser alcançado, tal como as revistas antigamente faziam. O que também é uma jogada do capitalismo para aumentar a produção e consumo de coisas que a gente não precisa”. (D.C.)

“Por ter baixa auto estima”. (P.S.S.)

"Bom, pelo menos no meu caso, é por não saber como dialogar de forma madura, (pois acho que me falta maturidade). As vezes a timidez é um grande obstáculo”. (C.S.)

"Pra sempre mostrarem que estão felizes e bem sucedidos". (A.I.R.P.)

"Por que talvez querem estar seguindo e inspirado em alguém famoso(a), estar nas mídias sociais, talvez mostrar pra sociedade uma pessoa que na verdade não é”. (L.S.)

"Por que não se sentem realizadas ou não sabem o que buscar na vida real, para que se sintam realizadas no âmbito pessoal”. (A.M.)

Apesar da variedade de respostas encontradas, percebe-se que grande parte destas, relaciona-se a uma busca por felicidade, satisfação pessoal, sucesso, realização e ânimo, como uma espécie de afeto virtual, ou seja, fatores ligados a autoestima, denotando claramente a relação que há atualmente entre estes dois fatores.

Destaca-se, a preocupação sobre o que os outros vão achar ou se os demais vão gostar, como meio para realização pessoal e visibilidade como via para conseguir novos seguidores que vejam-nos como inspiração para algo. No entanto tais fatores podem ser prejudiciais a partir do momento em que os indivíduos tornam-se alienados no mundo virtual.

Atenta-se ainda aos fatores citados sobre a alienação tecnológica. Ao alienar as pessoas da realidade, ocupar demasiadamente o tempo das mesmas, reduzindo o contato físico, o diálogo direto, do olho no olho, ao trocar a realidade pela virtualidade essas pessoas acabam 
se isolando do mundo real, as vezes da própria família, colegas de trabalho e dos desafios do dia-a-dia, dos problemas mais diretos.

O mundo virtual estimula muito as fantasias, algumas completamente fora do contexto da realidade, podendo contribuir para a alienação total das pessoas com sérios riscos para sua saúde física, mental e social.

Dentre as respostas encontradas, faz-se importante destacar ainda, as pessoas que são tímidas pessoalmente e por isso utilizam a internet, pois sentem-se mais confiantes para mostrar fotos, vídeos e opiniões por meio das telas digitais.

Assim, independente do fator que motive o indivíduo, sabe-se que todos sentem-se bem ao receber comentários positivos e 'validação' daquilo que é postado em suas redes sociais. Deve-se esclarecer que a preocupação levantada neste artigo não refere-se a sentir-se bem diante as reações dos telespectadores, mas em utilizar tal aprovação como medidor da felicidade individual. Em meio ao questionário realizado, a entrevistada F.S. (2020), relata sua relação com as redes sociais da seguinte forma:

"Já foi uma relação bem tóxica porque eu sempre admirava os corpos das outras pessoas e julgava o meu julgava meus traços físicos e sentia a necessidade de ser igual aquelas pessoas, eu odiava o que via no espelho, até que senti que isso estava realmente me afetando e parei de seguir vários perfis e me afastando um pouco, todo dia é dia de deixar esses perfis dessas redes de lado e reparar em si mesmo e se amar e se aceitar, ainda é algo em construção porque os danos causados não são fáceis de serem revertidos é realmente se reeducar." (F.S.,2020)

Uma afirmação similar encontra-se na resposta de M.N.S, ao afirmar que:

“A relação é conturbada. Por muito tempo sofri, passei tempos sem redes sociais porque me sentia inferior as outras pessoas, mas aos poucos estou evoluindo." (M.N.S, 2020)

E ainda, no relato de: 
"Ultimamente uso pouco, mas me sinto triste com o meu corpo quando vejo, os corpos padronizados me fazem acreditar que o meu corpo não está bom.” (K.S., 2020)

"Gosto das redes sociais, pois ela nos dá o privilégio da comunicação a longa distância, apesar de, eu não ser tão comunicativo. As vezes me sinto bem, mas grande parte das vezes eu sinto um fracassado, digo que o espelho e eu não somos bons amigos!" (C.L, 2020)

A partir dos relatos acima, percebe-se o quanto as pessoas tornam-se vulneráveis diante o que é exposto nas redes sociais. Diariamente, somos expostos a corpos perfeitos, relacionamentos perfeitos, lugares encantadores, enfim, uma realidade que atinge poucas pessoas e torna-se o ideal para muitas, que nem sempre conseguem alcançar tais conquistas e a frustração por não alcançar tais expectativas relacionam-se diretamente à forma como o indivíduo percebe a si mesmo, e consequentemente reflete em sua autoestima. Conforme foi dito por F.S. faz-se necessário um grande processo de aceitação própria, fator este que é construído dia após dia, de modo que a exposição do outro não afete a forma como a pessoa se perceba.

Obviamente também há pessoas que conseguem utilizar as mídias sociais de modo consciente e positivo, como pode-se perceber nas seguintes afirmações:

"Minha vida não se basea nas redes sociais, não preciso mostrar minha felicidade e quem eu sou para todos, e se isso me afeta? De jeito nenhum. Busco quem eu sou, e não apresentar alguém que não sou.” (L.S) (M.P)

"Não interajo muito, não me afeta, me aceito exatamente como sou".

"Ótima relação, gosto de usá-la a meu favor, aproveitar o que tem de bom, não me afeta em nada, temos que ser felizes do jeitinho que somos." (S.S)

"Como tudo na vida, a rede social tem seu lado positivo e negativo, se você tiver um psicológico fraco, claro que vai se sentir afetado pelo padrão que nos é imposto, mas se você sabe o quanto é capaz, você pode tudo". (J.S)

Compreende-se portanto que, o segredo está em aceitar-se diariamente como um ser em construção e aprendizado, ressaltando que o mais importante não está no exterior ou na 
opinião das outras pessoas, mas no interior, na auto aceitação e no amor-próprio, utilizando assim, as mídias sociais de modo coerente e para fins positivos.

\section{3- METODOLOGIA}

A pesquisa deste projeto enquadra-se como pesquisa de observação em campo com abordagem qualitativa. A pesquisa de campo caracteriza-se pelas investigações em que, além da pesquisa bibliográfica e/ou documental, se realiza coleta de dados junto a pessoas, com o recurso de diferentes tipos de pesquisa (FONSECA, 2002). Neste trabalho especificamente, realizou-se a pesquisa participante (processo no qual a comunidade participa na análise de sua própria realidade).

Além de estudos baseados em artigos e pesquisas de autores como Mackenzie e Wajcman (1995), realizou-se, como instrumentos para coleta de dados um questionário que tratava sobre a relação entre as redes sociais e a autoestima, sendo disponibilizado a 25 indivíduos da faixa etária de 13 a 49 anos, residentes na cidade de Dom Pedro- Maranhão, pela plataforma do Google Forms.app, disponível no link: https://forms.app/form/sfaoaecic7dagd5a9d6ib439.

Através destas perguntas, pode-se compreender melhor a relação entre os termos supracitados, de modo a verificar como um afeta o outro e consequentemente, relaciona-se ao indivíduo e sua auto percepção.

\section{4- RESULTADOS E DISCUSSÕES}

Ao iniciar as pesquisas sobre a relação existente entre a utilização das redes sociais e a autoestima dos indivíduos, pode-se perceber assim, que a relação que estabelecemos com o mundo externo desenvolve em nossa mente uma imagem de como acreditamos que ele seja.

Os fracassos e sucessos, os medos e inseguranças, as sensações físicas, os prazeres e desgostos organizam-se em uma imagem interna sobre sua própria pessoa. Quando temos uma visão negativa de nós mesmos, comumente damos importância aos dados que confirmem a nossa 
crença: exemplo disso acontece quando somos bombardeados com publicações positivas das redes sociais, pois comparamos a nossa vida cheia de defeitos com a vida "perfeita" de um perfil virtual.

No entanto, o que muitas pessoas não enxergam é que a grande maioria dos posts nas redes sociais mostram somente o que o dono do perfil deseja: por um lado, mostra apenas eventos positivos de sua vida e, por outro, distorce eventos negativos para que se pareçam com eventos positivos.

Como forma de exemplificar e compreender melhor tal situação, o questionário realizado envolveu diferentes faixas etárias, como apresentadas a seguir:

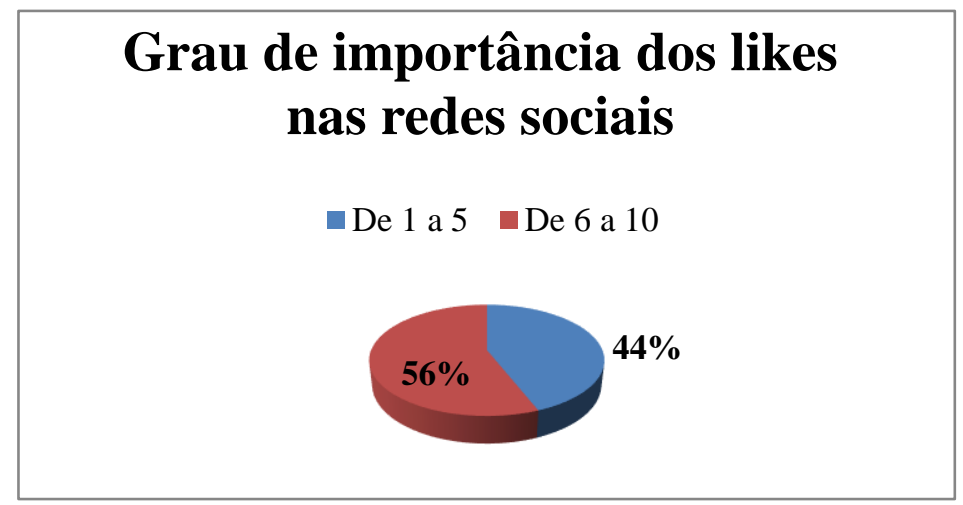

Apesar da diversidade na faixa etária, observou-se que todas elas tem essa preocupação com relação entre as redes pessoais, porém predominando na faixa etária de 13 a 20 anos, tendo em vista que, nesse período o adolescente está passando por um momento de transformação e identificação própria e do seu grupo social. Destes, I2\% afirmaram que realizam postagens diariamente em suas redes sociais. 
Os entrevistados foram questionados sobre o grau de preocupação dos mesmos a respeito dos likes em suas redes sociais, no qual obteve-se as seguintes respostas

\section{FAIXA ETÁRIA}

$\square 13$ a 20 anos $\quad 21$ a 30 anos $\square 31$ a 49 anos

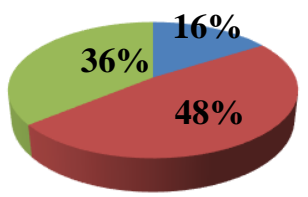

Além do número designado, os entrevistados também justificaram tal numeração, os quais, pode-se destacar:

"9. Então, não sou bom com Palavras mais isso faria eu me sentir um pouco mais amado, pois me sinto um tanto quanto solitário.” (C.S)

"5. Depende de como eu esteja me sentindo no momento em relação a autoestima”. (M.N.S.)

“6, porque desde de o ano passado que venho me importando menos com isso e deixando de ser muito ativa nessas redes sociais justamente pelos danos causados pela necessidade de atenção.” (F.S.)

“4, os likes não influenciam muito o que penso a meu respeito, pois nem sempre condizem com a real importância que as pessoas dão umas as outras." (A.M.)

“2. Não faz muita diferença pra mim.” (K.S.)

Desse modo, denota-se que pessoas que já possuem problemas com autoestima, utilizam-se das redes sociais para sentirem-se menos sozinhas e receber mais atenção dos demais, como meio de sentir-se mais acolhido. No entanto, pessoas que possuem uma carga emocional mais preparada, um amor próprio mais definido, não tendem a questionar-se devido as reações dos demais nas mídias sociais. 


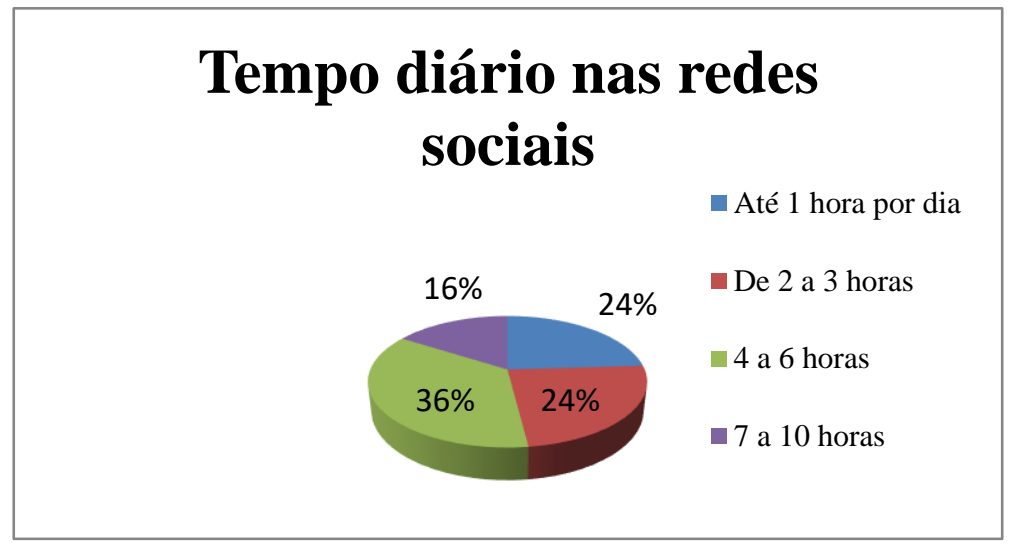

Ainda nesse quesito, os entrevistados demonstraram suas reações quanto a resposta dos demais com suas postagens, no qual estes afirmaram:

Não podemos negar que é satisfatório quando alguma postagem atinge um grande número de likes ou comentários, pois querendo ou não, estamos alienados a atual tecnologia e isso alimenta o nosso ego. (F.S)

Normal, não posto pra ser visualizada mundialmente, posto pra transmitir minha sensação de felicidade.(L.S.)

Quando as postagens não atingem os likes esperados, sinto como alguém que não tem relevância alguma na vida dos outros!. (C.S.)

Hoje me sinto normal, isso já foi de grande importância mas hoje eu só posto e deixo lá vou fazer qualquer outra coisa o importante é não fazer disso sua 'migalha de afago'.(J.S)

Assim, denota-se que instintamente, busca-se aprovação das outras pessoas, e mesmo quando não há esta intenção direta, surge uma sensação de felicidade e prazer ao sentir uma reação positiva dos demais, assim como surge uma certa tristeza e desapontamento quando isto não acontece.

Questionou-se ainda, a quantidade de tempo que os mesmos passam diariamente diante das redes sociais, obtendo-se os seguintes resultados:

Um fator que também trouxe revelações interessantes partiu da proposta de que os entrevistados relatassem, a visão que tinham a partir da imagem abaixo. 


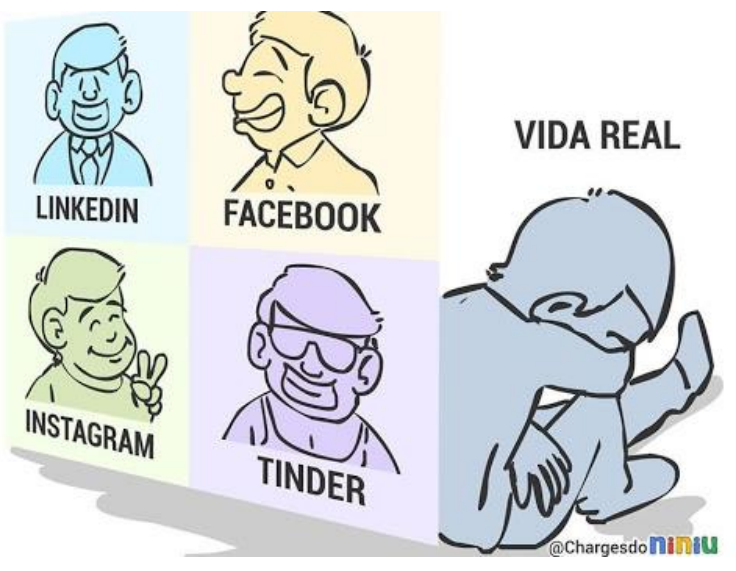

Dentre as respostas obtidas, pode-se citar:

A verdade é que as pessoas querem postar a todo custo que estão vivendo bem, e que isso é uma forma de mostrar felicidade. Os outros tem de ver que você está feliz, mesmo que não estejam. (J.O)

$\mathrm{Na}$ maioria das vezes, as pessoas passam uma imagem na rede social, mas por trás é totalmente diferente. Parece ter uma vida feliz, na verdade na vida real, está triste, deprimido. Ou seja, é tudo muito superficial. (S.S.)

A imagem representa a tentativa de uma felicidade falsa, pois muitas das vezes os contatos sociais criado pela rede gira em torno da aparência ou do status social que as pessoas tentam criar de si, o que as levam ao esquecimento de coisas mais importantes, como o afeto familiar. (A.M.)

Realmente é comum vermos na rede social, pessoas que estão a todo tempo procurando exibir uma vida que quase sempre não a mantém, devido estarem preocupadas com a aparência, e sobre o modo como quer que os outros o vejam, e assim como na imagem, fora das câmeras e flash, se vêem sem amigos e solitários.(J.S.)

Numa recente challenge onde as pessoas postavam as fotos de perfil que usavam de acordo com a rede social, sendo que em todos os casos as fotos mostravam um "personagem" sempre sorridente, de bem com a vida auto astral sendo que na realidade nua e crua são pessoas tristes com baixa autoestima e outros problemas psicológicos muito agravados pelo uso das redes onde os "personagens" com mais seguidores exibem suas vidas perfeitas e felizes fazendo seus expectadores sentirem a necessidade de montarem todo esse cenário de vida perfeita. (F.S.)

Nem sempre o que você é nas redes sociais coincide com a realidade. Até porque as redes sociais exigem uma pressão na forma de vida que deve ser apresentada nela. (D.C.) 
A imagem retrata bem a realidade da qual estamos vivenciando, pessoas que nas redes sociais demonstram felicidade, porém, fora delas são pessoas tristes. (M.P.)

Essa imagem mostra o que se passa na vida de muitas pessoas, aparentam o que não são. Postam fotos felizes mas por dentro estão tristes e passando por diversos problemas. (M.N.S.)

Estas constatações reforçam a ideia do envolvimento direto das redes sociais nos demais campos da vida pessoal, primordialmente no modo como o indivíduo se vê e como espera que os outros o vejam, idealizando uma falsa realidade apenas para encaixar-se nos padrões e manterem-se bem vistas pela sociedade virtual, deixando de lado o fator fundamental que é perceber-se consigo próprio a partir de suas próprias experiências e sensações.

Viver a partir do que se almeja do outro, torna-se frustrante e desgastante, resultando em problemas na autoestima e no desenvolvimento emocional, pessoal e social. Portanto, as redes sociais, podem e devem ser utilizadas, porém de forma positiva e voltada para o bem estar, agindo assim de forma equilibrada.

Conforme Carolina Vila Nova, colunista no site 'O Segredo':

"A exibição e ostentação de dinheiro mostra uma ausência de valores amorosos. Assim como a exibição e humilhação através da posse de dotes intelectuais, mostra a necessidade de subjugar o outro, compensando uma provável subjugação do passado. O excesso de sociabilidade, escancarando a necessidade de ser aceito, quando de forma inconsciente não há a aceitação por parte de si mesmo. E daí por diante. Não mudamos a história do nosso passado, mas somos capazes de mudar o que sentimos ao lembrar de nossas histórias. Transformamos nossas mágoas e dores em compreensão e aceitação. A partir daí, toda e qualquer necessidade de se sobressair desaparece.

Uma vez donos de nós mesmos, não importa, o que o mundo pensa ou o que o mundo fala. Só importa a paz finalmente encontrada no melhor lugar possível: em si mesmo!”. (VILA NOVA, 2018)

Em suma, a chave para viver bem neste mundo virtual, está na aceitação e amor próprio, fatores estes, que infelizmente encontram-se escassos. Em alguns casos, faz-se necessário buscar auxílio de um profissional que possa auxiliar o indivíduo a passar por este 
processo, esclarecendo que, o profissional em questão não irá fornecer as respostas prontas, visto que cada ser é único e individual, porém irá auxiliá-lo a encontrar as respostas necessárias dentro de si mesmo.

Neste sentido, para Guilhard (2002):

A autoestima é o produto de contingências de reforçamento positivo de origem social. Assim, sempre que uma criança se comporta de uma maneira específica, e os pais a consequenciam com alguma forma de atenção, carinho, afago físico, sorriso (cada uma dessas manifestações por parte dos pais pode ser chamada de reforço social generalizado positivo ou consequência positiva), estão usando contingências de reforçamento positivo, estão gratificando o filho. Por outro lado, toda vez que uma criança se comporta e os pais a repreendem, a criticam, se afastam dela, não a tocam, nem conversam com ela (cada uma dessas manifestações por parte dos pais pode ser chamada de estímulo aversivo ou consequência negativa), estão usando contingências coercitivas ou punindo o filho. A primeira condição aumenta a autoestima, a segunda a diminui.

Ela surge como uma necessidade adquirida e desenvolve-se a margem das experiências do self junto à satisfação e frustração da necessidade de estima. E, assim, independente do que o outro gosta, o indivíduo pode vir a experimentar a perda ou a estima; neste ponto, o marco referencial é o próprio indivíduo. A autoestima está em conexão com a estrutura total e complexa do self, isto quando experimentada em ralação a experiências do self (ROGERS, in MILLON, 1979).

O conceito de autoestima tem extrema relevância na Psicologia, apesar de não haver consenso na literatura em torno de sua definição. Dolan (2006) destaca que a autoestima é um dos conceitos psicológicos mais utilizados atualmente, provavelmente pelo seu aspecto prático na compreensão da busca de felicidade por parte das pessoas.

Portanto, ao perceber que há problemas ligados a este fator, faz-se necessário que haja em algum momento um STOP para uma reflexão sobre o que está acontecendo nesse momento em relação a vida, observando o que não está legal, o que o indivíduo deveria ou gostaria de fazer para alcançar seu objetivo. É preciso dedicar-se ao exercício de olhar para si mesmo 
com um olhar sincero, deixando de lado as artimanhas que comumente são usadas para fugir deste encontro, tais como os mecanismos de subestimação ou superestimação. $O$ ser humano é aquilo em que acredita. Os atrativos físicos não são o único aspecto importante para a sociedade. Outros valores, verdadeiros instrumentos de transformação do ser humano precisam ser mais desenvolvidos e praticados, para que o homem encontre sua verdadeira felicidade e comece a ter confiança em si mesmo elevando a sua autoestima, valores como: autenticidade, tolerância com os seus modos de ser e com o modo de ver o outro, empatia colocar-se no ugar do outro, ser solidário aos seus sentimentos e humildade.

\section{5- CONSIDERAÇÕES FINAIS}

A presente pesquisa engajou-se em identificar a relação existente entre as mídias sociais e autoestima dos indivíduos.

os estudos e questionários realizados, identificou-se que há uma íntima relação entre os pontos abordados. É sábio que neste momento de globalização, as mídias sociais então presentes no nosso cotidiano, auxiliando no acesso a informação e facilitando o contato com pessoas que encontram-se fisicamente distantes.

No entanto pode-se transformar em algo negativo, a partir do momento em que influi na forma como o indivíduo percebe a si mesmo. A autoestima mostra como o indivíduo vê o mundo que o cerca, e como ele reage a esse mundo, a esse ambiente. As experiências de uma pessoa, as relações estabelecidas com o ambiente de forma positiva ou punidoras fazem com que o indivíduo se comporte de uma determinada a essas história passada. Essas experiências constroem a autoestima da pessoa fazendo-a se comportar demonstrando nas relações a confiança, segurança e valor que o indivíduo dá a si mesmo.

Dessa forma, quando o indivíduo realiza postagens e/ou comentários que não recebem a aprovação esperada pelos outras, ocorre uma frustração que impacta negativamente o usuário, assim como surge uma sensação de prazer e felicidade momentânea ao conseguilos. 
Entende-se que o problema em questão não está no uso das mídias sociais, mas em usá-las como ponto de referência para a auto aceitação. Nas mídias sociais, o individuo acaba encontrando perfis de imagens idealizadas, que não são reais, e que são impossíveis de serem alcançadas, o que pode levá-lo ao sofrimento, pois ele pode criar, idealizar uma imagem de si impossível de ser atingida, muito distante de sua imagem real, do que ele é, o que o leva a um sentimento de frustação por não conseguir ser tão perfeito como os outros, e como ele próprio se imagina.

Portanto, faz-se necessário uma reflexão interna e um processo contínuo de aceitação e amor-próprio, de modo a entender que a beleza do mundo consiste exatamente nisto, na possibilidade de ser único e verdadeiro às suas raízes e sentimentos.

\section{6- REFERENCIAS}

BARROS Júnior, Antônio Carlos de. Quem vê perfil não vê coração: a ferida narcísica de desempregados e a construção de imagens de si no Facebook e no LinkedIn. Psicologia Social. Tese de Doutorado. Instituto de Psicologia. 2014

COSTA, Bruna Marangoni Brancaleone Costa, JUNIOR, Irineu Francisco Barreto. HIPEREXPOSIÇÃO PESSOAL NAS REDES SOCIAIS E SEUS REFLEXOS NO DIREITO. Revista de Direito, Governança e Novas Tecnologias | e-ISSN: 2526-0049 | Salvador |v. $4 \mid$ n. I | p. 92- Io8 | Jan/Jun. 2018

Dolan, S. (2006). Estresse, auto-estima, saúde e trabalho. Rio de janeiro: Qualitmark.

GABRIEL, Martha. Você, eu e os robôs: pequeno manual do mundo digital. São Paulo: Atlas, 2018.

MILLON, T. Teorias de psicopatologia e personalidade. Rio de Janeiro: Interamericana, 1979.

NOVA, Carolina Vila. Diga-me como você se exibe e eu lhe direi qual é o seu vazio! O Segredo, 27/o7/2018. Disponível em: https://osegredo.com.br/diga-me-como-voce-seexibe-e-eu-lhe-direi-qual-o-seu-vazio/

PRIMO, A. O que há de social nas mídias sociais? Reflexões a partir da teoria ator-rede. Revista: Contemporanea | comunicação e cultura - v.Io - n.03 - set-dez 2012. (p. 618-64I). Disponível em:< http://biblat.unam.mx/pt/verista/ contemporanea-salvador/articulo/o- 
Revista Ibero- Americana de Humanidades, Ciências e Educação- REASE open 2 Access

que-há-de--social-nas-midias-sociais-reflexoes-a-partir-da--teoria-ator-rede> Acesso em: 24 Abr. 2017

SILVA, Marina C. Questionário: Redes Sociais e Autoestima. Disponível em: https://forms.app/formresult/5faoaecic7da9d5a9d6rb439/records 


\section{ANEXO- QUESTIONÁRIO}

I- NOME:

2- IDADE:

3- De i a io que número você daria para a importância de likes em suas redes sociais? Justifique.

4- Que conteúdos você mais segue em redes sociais?

5- Apresente sua opinião sobre a imagem a seguir, presente em https://www.instagram.com/psicoshirleymacena/ :

6- Com que frequência você posta fotos e vídeos em suas redes sociais?

7- Como se sente quando suas postagens tem grande número de likes e visualizações?

8- Como se sente quando suas postagens não atingem o número de likes e comentários esperados? :

9- Em sua opinião, porque as pessoas buscam uma 'auto aprovação' dos demais nas redes sociais? 
Io- Como as redes sociais afetam, de fato, a autoestima das pessoas?

II- Qual é a sua relação com as redes sociais e como elas afetam a sua relação com você mesmo (a) e o espelho?

I2- Quantas horas por dia você passa em média, examinando, compartilhando e curtindo em suas redes sociais? Você considera que é pouco ou muito tempo? 